\title{
RUANG KOMUNAL KUE TRADISIONAL DI SENEN
}

\author{
Astrid Agustina ${ }^{1)}$, Sutarki Sutisna ${ }^{21}$ \\ 1)Program Studi S1 Arsitektur, Fakultas Teknik, Universitas Tarumanagara, astridjatnika@gmail.com \\ 2) Program Studi S1 Arsitektur, Fakultas Teknik, Universitas Tarumanagara, tarkisutisna@gmail.com
}

\begin{abstract}
Abstrak
Bangsa Indonesia patut berbangga, pasalnya makanan Indonesia dinobatkan sebagai makanan terenak di dunia selama beberapa tahun. Bangsa lain saja bahkan mengakui kelezatan warisan nenek moyang kita. Makanan tradisional Indonesia seperti rendang, sate, dan nasi goreng memang sudah dikenal dan diakui oleh negara lain, namun camilan dan kue tradisional masih kurang populer bahkan di generasi muda Indonesia sendiri. Seiring perkembangan kuliner, lebih sering kita temui kue-kue seperti tart, brownies, atau pie dibandingkan kue tradisional seperti kue bugis, kue apem, kue bikang. Tidak salah bila masyarakat Indonesia ingin terbuka dan mempelajari kue-kue asal barat, namun kita pun harus tetap melestarikan budaya sebagai identitas bangsa Indonesia di mata dunia. Jangan sampai kue-kue tradisional yang masih bisa ditemukan di pasar semakin menurun eksistensinya. Oleh karena itu, sebuah Third Place sebagai wadah yang dapat digunakan untuk memberikan pengetahuan dan pengenalan diperlukan di tengah-tengah generasi muda. Third Place sebagai ruang untuk berkumpul sangat diperlukan bagi manusia. Manusia sebagai makhluk sosial membutuhkan koneksi antara manusia lain. Kurangnya koneksi sosial bahkan dapat merusak kesehatan seorang manusia lebih besar dibandingkan obesitas, rokok, dan tekanan darah tinggi. Selain untuk bersosialisasi, Third Place juga dapat dijadikan sarana untuk edukasi, dengan tujuan agar semua masyarakat terutama generasi muda memiliki pengetahuan dan mengenal budaya memasak dan makanan tradisional mereka sendiri, khususnya kue tradisional.
\end{abstract}

\section{Kata kunci: kue tradisional; makanan Indonesia; sosial; third place}

\begin{abstract}
The Indonesian people should be proud, because Indonesian food has been named the most delicious food in the world for several years. Other nations even recognize our ancestral heritage. Indonesian traditional foods such as rendang, satay and fried rice are already wellknown and recognized by other countries, but traditional snacks and cakes are still less popular in Indonesia's young generation. Throughout culinary development, we often encounter cakes like tarts, brownies, or pies compared to traditional cakes such as bugis, apem cake, bikang cake. It is not wrong if Indonesian wants to know about cakes from the west country, but we must also preserve culture as the identity of the Indonesian people in the eyes of the world. Do not let the traditional cakes that can still be found in the market have decreased. Therefore, Third Place as a forum that can be used to provide knowledge and preparation is needed in the midst of the younger generation. Third place as a space to support is needed by humans. Humans need social assistance between other humans. Lack of social connections can damage human health more than obesity, smoking, and high blood pressure. In addition to socializing, Third Place can also be made for education purposes, with the aim that all people particularly young people have knowledge of their own culture and traditional foods, especially traditional cakes.
\end{abstract}

Keywords: Indonesian foods, social, third place, traditional cakes 


\section{PENDAHULUAN}

\section{Latar Belakang}

Indonesia adalah negara kepulauan terbesar di dunia dengan ribuan pulau tropis mulai dari beberapa yang terbesar di dunia hingga gugusan karang kecil yang terdampar di laut safir. Dengan gunung-gunung yang tertutup salju dan hutan hujan yang rimbun, padang gersang dan sawah irigasi, sulit untuk membayangkan moto nasional yang lebih tepat untuk bangsa ini selain Bhinneka Tunggal Ika - Persatuan Dalam Keanekaragaman. Dengan keragaman geografis dan budayanya yang sangat besar, tidak mengherankan jika makanan Indonesia juga sangat bervariasi. Hal ini dapat dimengerti, keragaman masakan Indonesia mendapat pengaruh asing yang dibawa oleh perdagangan internasional. Sepanjang sejarahnya, Indonesia memiliki pedagang yang membawa produk dari India, Timur Tengah, Tiongkok, dan Eropa, yang semuanya memiliki pengaruh besar pada masakan asli Indonesia.

Di berbagai kota besar lazim ditemui jajanan Tiongkok seperti bakpao, bakmi, dan bakso yang dijual baik oleh pedagang kaki lima di tepi jalan atau di restoran. Masakan Tiongkok sering kali diadaptasi menjadi masakan Indonesia. Salah satu contoh adaptasi ialah daging babi jarang digunakan, dan diganti daging sapi karena menyesuaikan dengan mayoritas warga Indonesia yang kebanyakan Muslim. Salah satu makanan jajanan pinggir jalan yang populer adalah siomay dan batagor, pempek, bubur ayam, bubur kacang hijau, sate, nasi dan mie goreng, toge goreng, laksa, dan gorengan. Jajanan pinggir jalan Indonesia juga mencakup berbagai minuman manis, seperti es cendol atau es dawet, es teler, es cincau, es doger, es campur, es potong, and es puter. Kue khas Indonesia sering disebut sebagai jajan pasar. Indonesia memiliki kekayaan berbagai macam kudapan, dan kue, baik gurih maupun manis. Kue populer di antaranya risoles, pastel, lumpia, lemper, lontong, tahu isi, lapis legit, getuk, bakpia, bika ambon, lupis, lemang, timpan, klepon, onde-onde, nagasari, soes, dan bolu kukus. Kue khas Indonesia dapat kita jumpai di pasar-pasar tradisional oleh karena itu sering disebut jajanan pasar atau jajanan tradisional.

Keberagaman kuliner Indonesia amat berhaga sehingga perlu untuk dilestarikan. Namun, di tengah kemajuan zaman pada teknologi industri 4.0 tidak menutup kemungkinan, makanan warisan nenek moyang yang diwariskan tidak akan dikenal lagi oleh generasi muda, karena akan digantikan makanan ala Eropa atau makanan lainnya. Merebaknya makanan kekinian makin mengikis minat terhadap jajanan tradisional, khususnya di kalangan anak muda zaman sekarang. Padahal, jajanan tradisional pun tidak kalah enak dengan makanan kekinian. Dalam acara seri Street Food garapan Netflix, jajanan pasar masih familiar dengan milenial, tapi bagi gen Z, barulah terlihat tantangan di sana. Pasalnya, orangtua generasi ini bisa dikatakan sudah modern. "Terlebih, anak-anak ini (gen Z) lahir ketika lifestyle dinning sedang booming. Ditambah sekarang dimanjakan dengan food delivery. Memori berburu jajanan pasar bisa jadi tidak relate dengan mereka," jelas Kevindra Soemantri, salah seorang food blogger asal Indonesia. Gaya hidup modern yang tergila-gila dengan segala sesuatu yang global ini, tambah Kevindra, tengah jadi kekhawatiran banyak negara di dunia yang memiliki kultur kuliner kuat, tak terkecuali Indonesia.

\section{Rumusan Permasalahan}

a. Bagaimana kue tradisional digunakan sebagai dasar menentukan Third Place?

b. Bagaimana menjadikan ruang komunal sebagai tempat mensosialisasikan kue tradisonal?

c. Bagaimana konsep Third Place diterapkan dalam perancangan ruang komunal?

\section{Tujuan}

a. Menerapkan kue tradisional dalam menentukan program Third Place.

b. Membuat desain perancangan ruang komunal dengan konsep Third Place.

c. Membuat desain perancangan Ruang Komunal Kue Tradisional di Senen sesuai dengan karakter Third Place. 


\section{KAJIAN LITERATUR}

\section{Third Place}

Ray Oldenburg dalam bukunya yang berjudul "The Great Good Place" menjelaskan apa yang dimaksud dengan Third Place, "Third Place, where people can gather, put aside the concerns of work and home, and hang out simply for the pleasures of good company and lively conversation - are the heart of a community's social vitality and the grassroots of democracy. "Ray Oldenburg (1999) menyatakan bahwa Third Place merupakan tempat untuk orang yang ingin mengobati stres, kesepian, dan keterasingan. Third Place adalah sebuah tempat yang bertujuan untuk memenuhi kebutuhan manusia untuk berkumpul atau berkomunitas yang bersifat informal dan publik. Tempat ini menjadi bagian dari bentuk kota dari kehidupan sehari-hari masyarakat. Pada Third Place membuat orang-orang untuk melarikan diri dari First Place (rumah) dan Second Place (tempat kerja atau sekolah) untuk membuka pikirian sendirinya serta bertujuan untuk bersosialisasi dengan orang lain maupun teman sendiri. Berdasarkan penelitiannya, Oldenburg (1999) mengungkapkan 8 karakter yang membentuk Third Place yaitu:

a. On neutral ground

b. Leveler

c. Conversation is the main activity

d. Accessibility and accommodation

e. The regular

f. Low profile

g. Mood is playful

h. A home away from home

\section{Ruang Komunal}

Komunal memiliki arti bersangkutan dengan komune; milik rakyat atau umum (KBBI). Dalam kamus Oxford, kata 'communal' berarti "shared by all members of a community; for common use." Ruang komunal merupakan ruang publik atau ruang umum yang didefinisikan sebagai ruang terbuka yang bebas diakses oleh siapa saja, dimana setiap individu maupun kelompok dapat melakukan berbagai aktivitas berkumpul dan berinteraksi (Carr, 1992). Menurut Lang (1987), ruang komunal memberikan kesempatan kepada orang untuk bertemu, tetapi untuk menjadikan hal itu diperlukan beberapa katalisator. Katalisator mungkin secara individu yang membawa orang secara bersama-sama dalam sebuah aktifitas, diskusi atau topik umum. Sebuah ruang terbuka publik akan menarik orang jika terdapat aktifitas dan orang dapat menyaksikannya. Ruang komunal sudah lama menjadi bagian arsitektur kota. Salah satunya adalah alun-alun Meksiko yang merupakan peninggalan berumur empat ribu tahun yang sangat kaya akan budaya. Alun-alun ini adalah jantung dari setiap lingkungan dan kota-kota Meksiko. Plaza adalah bagian dari ruang terbuka komunal sakral yang mencakup biara (teras atau altar suci dan atrium gereja) dan terkadang alun-alun kota atau pasar. Ruang komunal terbuka menjadi tempat adanya pertemuan antara teman baru dan lama, di mana orang pergi untuk melihat apa yang tren, dan di mana ritual dan perayaan setempat terjadi, di mana sejarah dan sense of place selalu ada.

\section{Kue Tradisional Indonesia}

Menurut Kamus Besar Bahasa Indonesia, kue memiliki arti penganan yang dibuat dari bahan yang bermacam-macam, dapat dibuat dalam berbagai bentuk. Kata "kue" yang berasal dari kata serapan dari bahasa Hokian ini menunjukan pengaruh seni memasak Tionghoa di Nusantara. Beberapa kue menunjukan asal usulnya dari Cina seperti kue bakpia. Kebanyakan kue basah adalah kue khas Nusantara, sementara untuk beberapa kue lain menunjukan pengaruh dari Eropa yaitu Belanda dan Portugis. Awalnya istilah kue memang digunakan untuk menyebutkan nama kue tradisional dan kue keturunan Tionghoa, akan tetapi dalam bahasa Indonesia istilah ini telah meluas menjadi istilah yang memayungi makanan ringan, termasuk untuk menyebut 
kue kering, kue pastri, dan kue tart atau kue bolu. Kue tradisional diolah dengan cara dikukus, dipanggang, atau digoreng. Kue-kue di Indonesia biasanya dikategorikan berdasarkan keadaan yaitu kue basah dan kue kering. Umumnya kue basah bertekstur empuk dan tidak dapat bertahan lama, hal ini dikarenakan komposisi dari kue basah seperti tepung beras, gula pasir, dan santan sehingga mudah basi dan juga kue basah ini diolah dengan cara dikukus, direbus, atau digoreng. Nama "kue basah" mewakili sifat kue-kue Indonesia yang pada umumnya dimatangkan dengan uap air mendidih (cara kukus) sehingga kue menjadi lembab dan terkesan basah. Inilah ciri khas yang membedakan kue Indonesia dengan kue gaya barat.

\section{METODE}

Metode pengumpulan data yang digunakan oleh penulis adalah sebagai berikut.

a. Studi lapangan

Studi lapangan dilakukan dengan cara mengamati langsung kondisi di sekitar tapak, mengidentifikasi kondisi eksisting tapak, dan potensi yang dapat mendukung rancangan dan juga mengidentifikasi permasalahan yang terjadi di lokasi.

b. Wawancara

Wawancara dilakukan di Pasar Kue Subuh Senen kepada 5 orang pedagang yang berjualan di Pasar Kue Subuh Senen.

c. Survey dan dokumentasi

Survey dilakukan kepada 50 orang responden yang berusia 15-35 tahun. Usia 15-35 tahun dipilih karena termasuk dalam generasi milenial dan generasi Z, orang-orang yang berusia diatas 35 tahun dianggap mengetahui dan mengenal kue tradisional.

d. Studi literatur

Studi literatur yang digunakan sebagai referensi berupa buku, jurnal, artikel, dan karya ilmiah lainnya. Literatur yang digunakan adalah yang memiliki informasi tentang tapak, Third Place, maupun kue tradisional.

e. Studi Preseden

Studi preseden yang digunakan adalah yang memiliki kemiripan besaran tapak, program kegiatan, iklim dengan proyek Third Place.

Setelah mendapatkan data, penulis selanjutnya melakukan analisis perancangan. Di dalam analisis perancangan terdapat tiga analisis, yaitu analisis tapak, aktivitas dan program. Metode perancangan yang digunakan dalam proyek Ruang Komunal Kue Tradisional di Senen adalah dengan pendekatan metafora. Pendekatan metafora arsitektur terbagi dalam 3 kategori, yakni:

a. Metafora tak teraba (Intangible Metaphor)

Yaitu memetaforakan sesuatu yang tidak dimunculkan dalam bentuk arsitekturnya melainkan diwujudkan dalam konsep, ide, sebagian kondisi atau sebagian karakter;

b. Metafora teraba (Tangible Metaphor)

Yaitu memetaforakan sesuatu yang dimunculkan secara langsung dalam bentuk arsitekturnya atau materialnya; dan

c. Metafora kombinasi (Combined Metaphor)

Yakni metafora yang merupakan gabungan antara metafora langsung dan tidak langsung, baik melalui konsep, ide, persepsi, atau bentuk.

\section{DISKUSI DAN HASIL}

\section{Konsep Perancangan}

Hubungan antara makanan dan arsitektur menarik untuk ditelusuri. Pergerakan dari kegiatan 'memakan' selalu beriringan dengan nilai dari ruang yang melingkupinya. Makanan dan kegiatan 'memakan' telah bergerak dari sekadar sebuah kebutuhan primer menjadi sesuatu yang mempunyai nilai simbolik. Makanan menjadi sebuah obyek yang menandai terjadinya upaya intervensi pada struktur sosial di satu periode waktu; saat prosesi memakan 
itu berlangsung. Kegiatan 'memakan' makanan ini menjadi sebuah prosesi yang memberikan arah pada proses penandaan tersebut. Pihak mana yang menyajikan, cara menyajikan, dan dengan cara bagaimana makanan tersebut diberikan, diambil dan dimakan adalah satu rangkaian tanda yang mengekspresikan sebuah pesan. Dalam kegiatan "memakan" ini, makanan dan proses memakannya menghadirkan makna pada ruang dan tempat. Menariknya, demikian pula arsitektur. Kelahiran arsitektur ditandai dengan lahirnya dan hadirnya sebuah makna dari sebuah ruang pada bangunan. Pada konteks arsitektur, makna dari sebuah ruang hadir melalui relasi ruang dalam dan ruang luar, Pengaturan ruang, Kepekaan terhadap skala, material, detail, tektonika dan, yang terutama, adalah empati dari si pengguna terhadap ruang. Artikulasi Kebutuhan akan makna dalam konsep eksistensi ini yang kemudian menjadi mata rantai penghubung antara Makanan dan Arsitektur.

Arsitektur membutuhkan kehadiran makna, dan Prosesi Memakan dan Makanan adalah sebuah entitas yang mampu memproduksi makna. Situasi ini memungkinkan terciptanya sebuah relasi mutualisme antara perancangan arsitektur dan prosesi memakan makanan. Dalam melakukan pendekatan rancang banyak cara yang dapat digunakan, salah satunya adalah dengan sudut pandang metafora. Metafora yang digunakan dalam Ruang Komunal Kue Tradisional di Senen adalah Metafora Kombinasi dan karakter yang diambil adalah proses memasak kue tradisional dengan cara pengukusan. Teknik pengolahan kue tradisional yang sering digunakan adalah teknik mengukus. Mengukus adalah teknik mematangkan makanan menggunakan uap air yang mendidih. Mengukus termasuk teknik memasak menggunakan cairan atau uap air (moist cooking method). Makanan atau kue yang dihasilkan dari teknik memasak ini biasanya basah atau lembab dan lunak atau lembut. Dilihat dari segi teknik, mengukus tergolong cara memasak yang mudah.

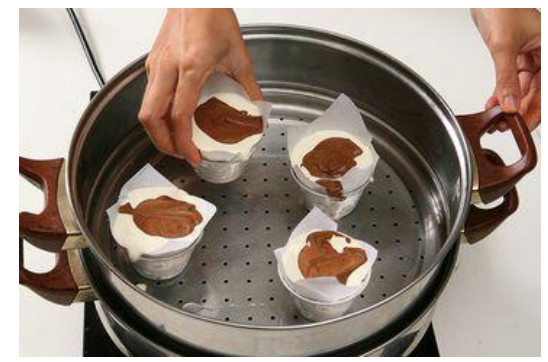

Gambar 1 Proses Mengukus Kue Mangkok

Sumber: https://sajiansedap.grid.id/read/10993668/tips-mengukus-kue-ini-panduan-lengkapmengukus-kue-dari-besar-lubang-kukusan-hingga-jumlah-air?page=all diakses 12 Juli 2020.

Mangkok memiliki bentuk yang semakin lebar ke atas seperti gambar di atas. Lalu dibawah massa bangunan diberikan unsur air untuk melambangkan air kukusan. Karakter lain yang muncul di dalam proyek Third Place ini adalah kukusan anyaman bambu karena kue tradisional yang ada di Indonesia mendapat pengaruh dari budaya Tionghoa, baik dari proses memasak, bahan yang digunakan, bahkan tampilan. Dalam panganan Tionghoa yang dikukus biasanya orang-orang Tionghoa menggunakan kukusan yang terbuat dari anyaman bambu ini.

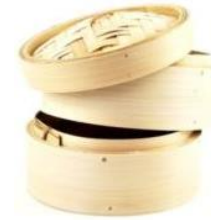

Gambar2. Kukusan Anyaman Bambu

Sumber: https://www.alibaba.com/product-detail/wholesale- cookware-mini-dim-sumbamboo_60454362131.html diakses 12 Juli 2020. 

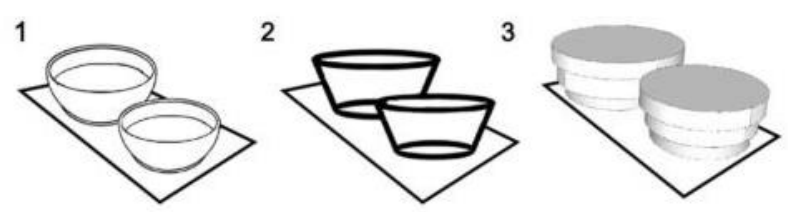

Gambar 3. Proses Gubahan Massa

Sumber: Data Pribadi, 2020

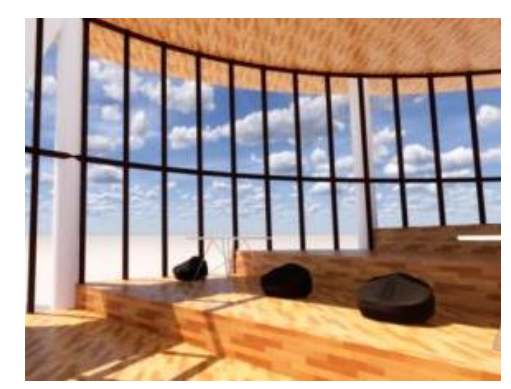

Gambar 4. Detail Communal Space

Sumber: Data Pribadi, 2020

Communal Space memiliki bentuk berundak menyerupai tangga, hal ini bertujuan untuk membuat semacam ampitheater. Di lantai yang di paling bawah dapat digunakan sebagai live music atau demo masak, sementara penonton bisa duduk menikmati dari Communal Space.

\section{Program Ruang}

Tabel 1. Program Ruang

\begin{tabular}{|c|c|c|c|}
\hline Ruang & Standar & $\begin{array}{l}\text { Luas Ruang } \\
\text { Berdasarkan }\end{array}$ & Luas \\
\hline \multicolumn{4}{|c|}{ Fasilitas Utama } \\
\hline Ingredients Market & NEUFERT & 100 & 160 \\
\hline Traditional Cake Exhibition & - & - & 118 \\
\hline Food Plaza & NEUFERT & 2 & 335 \\
\hline Experiment Kitchen & NEUFERT & 10 & 83 \\
\hline Communal Space & - & - & 545 \\
\hline \multicolumn{4}{|c|}{ Fasilitas Pendukung } \\
\hline Spices Garden & NEUFERT & 55 & 108 \\
\hline Food Stall & - & - & 109 \\
\hline Kantor & NEUFERT & 4 & 40 \\
\hline Ruang Rapat & NEUFERT & 15 & 36 \\
\hline Coffee Shop & - & - & 97 \\
\hline \multicolumn{4}{|c|}{ Servis } \\
\hline Toilet (Total) & NEUFERT & 2 & 132 \\
\hline Gudang & NEUFERT & 1,5 & 35 \\
\hline Ruang Genset dan Trafo & MEE & 80 & 11 \\
\hline Ruang CCTV dan panel & NEUFERT & 25 & 16 \\
\hline STP & - & - & 14 \\
\hline GWT dan Pompa & MEE & 40 & 19 \\
\hline Loading Barang & - & - & 150 \\
\hline Parkir Mobil & NEUFERT & 25 & 56 \\
\hline Parkir Motor & NEUFERT & 2 & 14 \\
\hline Parkir Sepeda & - & - & 23 \\
\hline \multicolumn{3}{|c|}{ Luas } & 2101 \\
\hline \multicolumn{3}{|c|}{ Sirkulasi } & 420,2 \\
\hline \multicolumn{3}{|c|}{ Luas Total } & 2521,2 \\
\hline
\end{tabular}

Sumber: Data Pribadi, 2020 


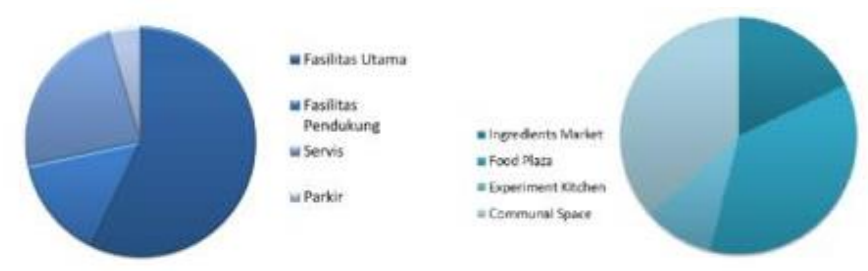

Gambar 5. Persentase Ruang

Sumber: Data Pribadi, 2020

\section{Struktur dan Material}
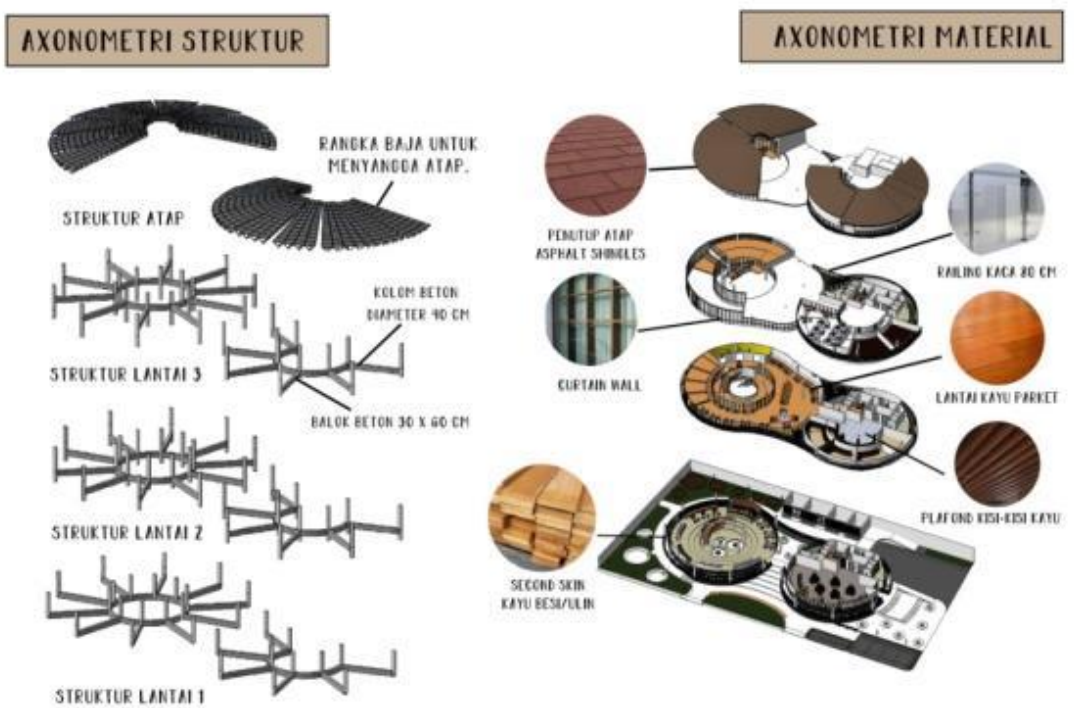

Gambar 6. Axonometri Struktur dan Material Sumber: Data Pribadi, 2020

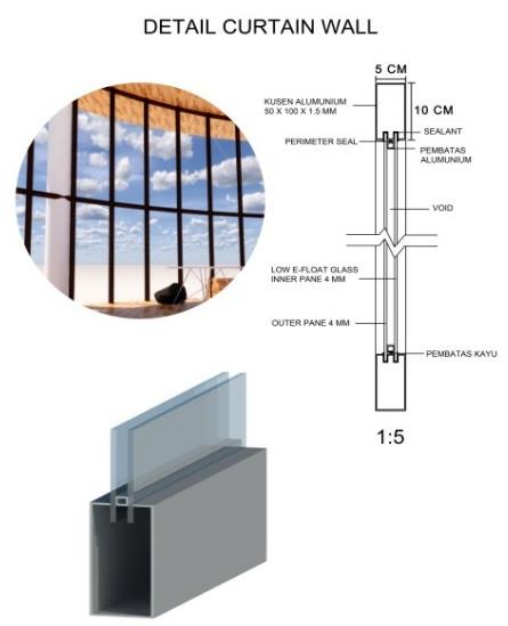

Gambar 7. Detail Curtain Wall di Food Plaza dan Communal Space (lantai 2 dan 3). Sumber: Data Pribadi, 2020 


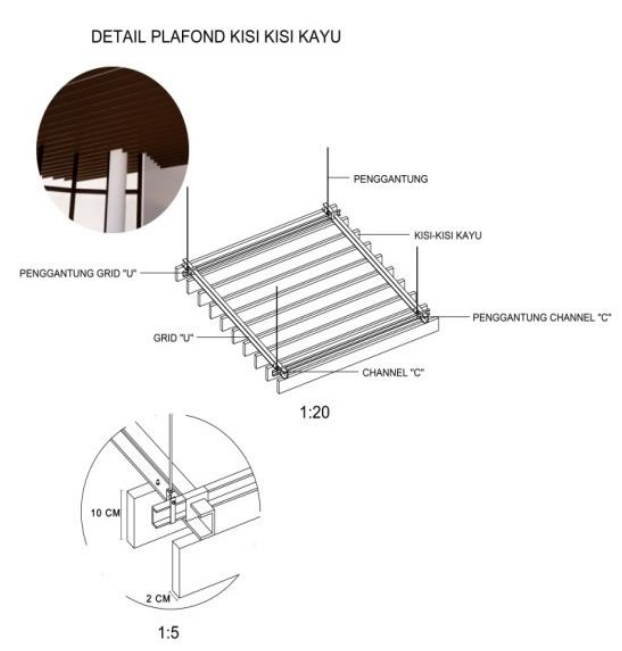

Gambar 8. Detail Plafond Kisi-Kisi Kayu, di Ingredients Plaza dan lobby lift lantai 2 dan 3 Sumber: Data Pribadi, 2020

\section{Perspektif Eksterior}

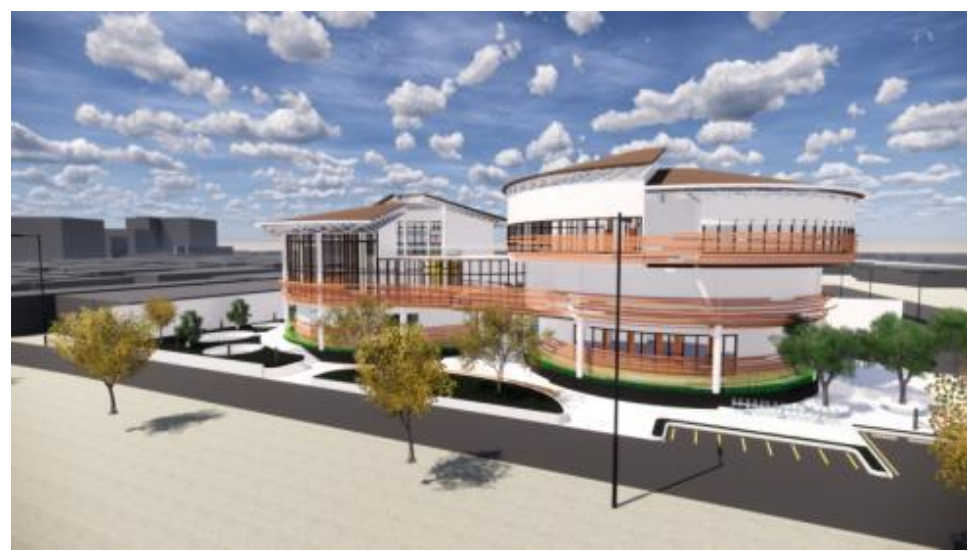

Gambar 9. Perspektif Eksterior 1

Sumber: Data Pribadi, 2020

\section{KESIMPULAN DAN SARAN}

\section{Kesimpulan}

Seiring perkembangan kuliner, lebih sering kita temui kue-kue seperti tart, brownies, atau pai dibandingkan kue tradisional seperti kue bugis, kue apem, kue bikang. Tidak salah bila masyarakat Indonesia ingin terbuka dan mempelajari kue-kue asal barat, namun kita pun harus tetap melestarikan budaya sebagai identitas bangsa Indonesia di mata dunia. Jangan sampai kue-kue tradisional yang masih bisa ditemukan di pasar semakin menurun eksistensinya. Oleh karena itu, sebuah Third Place sebagai wadah yang dapat digunakan untuk memberikan pengetahuan dan pengenalan tentang kue tradisional diperlukan di tengah-tengah generasi muda. Third Place sebagai ruang untuk berkumpul sangat diperlukan bagi manusia. Manusia sebagai makhluk sosial membutuhkan koneksi antara manusia lain. Kurangnya koneksi sosial bahkan dapat merusak kesehatan seorang manusia lebih besar dibandingkan obesitas, rokok, dan tekanan darah tinggi.

Selain untuk bersosialisasi, Third Place juga dapat dijadikan sarana untuk edukasi, dengan tujuan agar semua masyarakat terutama generasi muda memiliki pengetahuan dan mengenal budaya memasak dan makanan tradisional mereka sendiri, khususnya kue tradisional. Proyek Third Place Ruang Komunal Kue Tradisional di Senen ini sesuai dengan permasalahan yang terjadi di 
masyarakat muda masa kini. Ruang Komunal Kue Tradisional di Senen ini terletak di dekat Pasar Kue Subuh Senen yang merupakan salah satu sentra kue tradisional di Jakarta yang masih cukup ramai hingga kini.

\section{Saran}

Sebagai generasi muda, kita memang harus terbuka dengan budaya baru, namun juga tidak boleh melupakan budaya kita sendiri. Dengan adanya proyek Ruang Komunal Kue Tradisional di Senen ini diharapkan generasi muda dapat mengetahui dan mengenali kue-kue tradisional Indonesia. Third Place di dalam kehidupan manusia semakin diperlukan untuk bersosialisasi dan melepaskan penat. Seiring semakin berkembangnya teknologi, manusia semakin individualis, Third Place sangat berperan sebagai wadah percakapan antara manusia. Dalam merancang sebuah Third Place, menganalisis First Place dan Second Place masyarakatnya sangat penting. Third Place harus hadir di antara First Place dan Second Place. Setelah itu, harus mengetahui permasalahan apa yang terjadi di lingkungan Third Place ataupun yang terjadi di antara masyarakat kebanyakan. Dari permasalahan inilah kita dapat menentukan program kegiatan yang cocok untuk menyelesaikan permasalahan yang terjadi di masyarakat.

\section{REFERENSI}

Arrumaisa, N et. al. (2014). Pendekatan Rancang Metafora dalam Perancangan Kafe dan Karaoke. Institut Teknologi Sepuluh Nopember, G-57-58.

Arsana, L. dan Holzen, H. V. (2006). Authentic Recipes from Indonesia: 79 Easy and Delicious Recipes from the Spice Islands. Hongkong: Periplus Editions.

Box, H et. al. (2013). Ancient Origins Of The Mexican Plaza: From Primordial Sea To Public Space. Texas: University of Texas Press.

Carr, S. dkk. (1992). Public Space. Cambridge: Cambridge University Press.

Coughlin, J. (2019). 3 Food Trends Inspired by Millennials That Older Consumers Are Eating Up, Forbes. Retrieved July 4, 2020, from https://www.forbes.com/sites/josephcoughlin/2019/06/09/3-food-trends-inspired-bymillennials-that-older-consumers-are-eating-up/\#9318af37b963

Dina. (2017). Teknik Pembuatan Kue Tradisional Ini Mempercantik Tampilan dan Menaikkan Cita Rasa Camilan, Sajian Sedap. Diakses 15 Februari 2020, dari https://sajiansedap.grid.id/read/10756642/teknik-pembuatan-kue-tradisional-inimempercantik-tampilan-dan-menaikkan-cita-rasa-camilan?page=all

Gardjito, M. dkk. (2017). Makanan Tradisional Indonesia Seri 1: Kelompok Makanan Fermentasi dan Makanan yang Populer di Masyarakat. Yogyakarta: Gadjah Mada University Press.

Holzen, H. V. (2014). A New Approach to Indonesian Cooking. Singapura: Marshall Cavendish Cuisine.

Hutama, D. (2010, 7 Februari). Ekonomi, Makanan, dan Arsitektur. Kompas, p. 14.

Kidosm. (2018). 7 Makanan Kekinian VS Jajanan Tradisional: Kamu Masuk Geng yang Mana Nih?. Diakses 4 Juli 2020, dari https://www.qraved.com/journal/food-lol/7-makanankekinian-vs-jajanan-tradisional-kamu-masuk-geng-yang-mananih?from=line\&utm source=Line\&utm medium=CP\&utm campaign=LineRSSFeed

Kohll, A. (2018). Why Millennials Are Good For Employee Well-Being, Forbes. Retrieved July 4, 2020, from https://www.forbes.com/sites/alankohll/2018/10/03/why-millennials-aregood-for-employee-well-being/\#7792d7d41da5

Lang, J. (1987). Creating Architectural Theory. New York: Van Nostrand Reinhold Company.

Maharani, E. (2020). Jajanan Tempo Dulu Hadir di Festival Jajanan Tradisional. Diakses, 3 Juli 2020, Republika, https://republika.co.id/berita/q5fw6z335/jajanan-tempo-dulu-hadir-difestival-jajanan-tradisional 
Oldenburg, R. (1989). The Great Good Place: Cafés, Coffee Shops, Community Centers, Beauty Parlors, General Stores, Bars, Hangouts, and How They Get You Through The Day. Minnesota: Paragon House.

Raharjanti, R. (2011). Travelicious Jakarta: Jalan Hemat, Jajan Nikmat. Yogyakarta: B-First.

Riani, A. (2019). Cerita Akhir Pekan: Jajanan Pasar dan Eksistensinya di Kalangan Anak Muda. Diakses Juli 2020, 3 dari Liputan 6, https://www.liputan6.com/lifestyle/read/4062303/cerita-akhir-pekan-jajanan-pasar-daneksistensinya-di-kalangan-anak-muda.

Yasa, B. (2015). Kue-Kue Indonesia: 165 Resep Penganan Populer Nusantara. Jakarta: Gramedia Pustaka Utama. 